\title{
Life-threating outcomes after dental implantation in patient with idiopathic thrombocytopenic purpura: a case report and review of literature
}

\author{
Sung-Tak Lee, Jin-Wook Kim and Tae-Geon Kwon *i)
}

\begin{abstract}
Background: Patients with chronic ITP (idiopathic thrombocytopenia) frequently do not require comprehensive medication for daily life. Usually, it had been regarded that postoperative bleeding after a simple or surgical extraction is easily controlled by simple local measures even in patients with ITP. This lack of regular medication usage can sometimes lead practitioners or patients to underestimate the potential life-threatening risk of ITP. There had been no report on postoperative hemorrhage in a patient with ITP related to dental implant surgery.

Case presentation: This report presented a life-threatening postoperative hemorrhage after dental implant surgery in an adult with chronic ITP and subsequent emergency management after severe bleeding and airway compromise.

Conclusion: The presented case emphasizes the thorough hematological evaluation of the patients even for patients who do not take any specific medications for asymptomatic, chronic ITP.
\end{abstract}

Keywords: Thrombocytopenia, Idiopathic, Dental implant, Bleeding

\section{Background}

Idiopathic thrombocytopenic purpura (ITP) is a relatively common and easily recognizable acquired autoimmune disorder that presents with a low platelet count. It is characterized by the immune-mediated destruction of platelets by autoantibodies and the inhibition of platelet release from megakaryocytes. A normal platelet count ranges from 150,000 to $450,000 / \mu \mathrm{L}$, and lower counts are typically referred to as thrombocytopenia. Low platelet counts often lead to severe postoperative bleeding, spontaneous mucosal bleeding, cutaneous ecchymosis, retinal hemorrhage, and even life-threatening bleeding [1]. The ITP guideline panel of the American Society of Hematology estimated that patients with platelet levels below $30,000 / \mu \mathrm{L}$ have an approximately $5 \%$ risk of fatal hemorrhage over their lifetime [2]. However, considering

\footnotetext{
* Correspondence: kwondk@knu.ac.kr

Department of Oral and Maxillofacial Surgery, School of Dentistry,

Kyungpook National University, 2177 Dalgubeol-daero, Jung-gu, Daegu 41940, Republic of Korea
}

the large variations in bleeding risk among different age groups, the risk of fatal hemorrhage is likely to be even higher than this estimate [3].

Despite the potential risk, many patients with ITP need only close medical observation without special treatment. Because spontaneous bleeding is rare unless the number of platelets is $<30,000 / \mu \mathrm{L}$, therapeutic intervention is typically performed only when the platelet count falls below this level [4]. Therefore, a surgical procedure is not necessarily safe for a patient who is not being treated with a transfusion or medication. Before performing a surgical procedure, it is necessary to identify the family and medical histories, medication status, and detailed history of any bleeding tendency. Postoperative bleeding after oral surgery occurs in $8.6-32.1 \%$ of patients with compromised hemostasis [5].

Postoperative bleeding has been reported in patients with ITP after minor oral surgical procedures such as crown lengthening, cyst enucleation, and tooth extraction $[6,7]$. The risk of a fatal bleeding event in a patient 
with a low platelet count is reportedly relatively high. Moreover, patients with ITP and persistent low platelet counts have a poor prognosis [8]. However, a previous study suggested that postoperative bleeding after a simple or surgical extraction is easily controlled by simple local measures in patients with ITP [9].

No study has been conducted on postoperative hemorrhage in a patient with ITP related to dental implant surgery. The present case report describes a life-threatening outcome after implant surgery in a patient with ITP and reviews the adequate management thereof.

\section{Case presentation}

A 55-year-old man with a past history of ITP and hypertension visited a local dental clinic. Four years earlier, the patient had undergone knee joint surgery and was diagnosed with ITP. Because his platelet count was maintained at $35,000 / \mu \mathrm{L}$ thereafter and no spontaneous bleeding occurred, the patient attended periodic follow-up visits to check his platelet level but was not treated with any medication. The patient underwent extraction of the left mandibular first molar because of chronic periodontitis. Post-extraction bleeding occurred for 1 week after the procedure, but the hemorrhage gradually decreased and was finally controlled by a suture at the extraction site. After the extraction, the patient's platelet count was evaluated and maintained at $35,000 / \mu \mathrm{L}$.
One month after the extraction, the patient underwent dental implant surgery at the same site (the left mandibular first molar) at the same local dental clinic. Bleeding started immediately after fixture installation and the mouth floor began to swell. Therefore, the patient visited the emergency room (ER) of the authors' hospital. The patient was prescribed medication to control hypertension but no medication for ITP. The patient complained of severe swelling on the mouth floor and shortness of breath accompanied by marked dysphagia, which had also occurred immediately after the surgery. Bilateral submandibular swelling and mouth-closing difficulty were present (Fig. 1).

Regarding vital signs, his blood pressure was 173/ $108 \mathrm{mmHg}$ and the respiratory rate was $22 / \mathrm{min}$. A laboratory blood workup revealed a white blood cell count of $4.38 \times 10^{3} / \mu \mathrm{L}$, a hemoglobin $(\mathrm{Hb})$ level of $11.7 \mathrm{~g} / \mathrm{dL}$, and an initial platelet count of $22,000 / \mu \mathrm{L}$. Coagulation studies revealed that fibrinogen levels $(114 \mathrm{mg} / \mathrm{dL})$ were lower than normal, and D-dimer levels were elevated at $31.91 \mu \mathrm{g} / \mathrm{mL}$. Prothrombin time (PT) and activated partial thromboplastin time (aPTT) were within normal limits. A diagnosis of exclusion for ITP was made by the hematologist after ruling out other conditions that may cause symptoms similar to those of thrombocytopenic purpura. Because the patient had no past history of other contributing medication or medical condition and the results of laboratory tests showed a low platelet

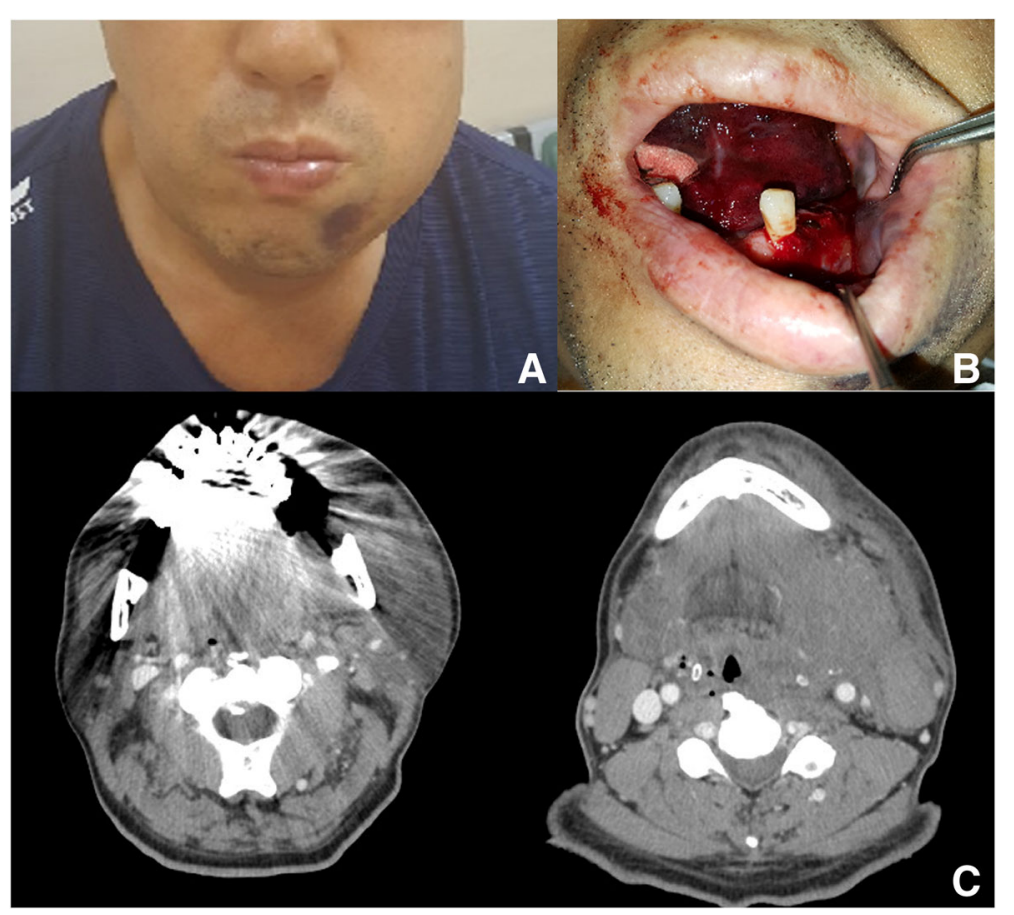

Fig. 1 a Facial swelling of an emergency room arrival. b Intra-oral view: mouth floor elevation and bleeding at the implantation site. c CT axial view showed severe narrowing pharyngeal airway due to soft tissue swelling in the left masticatory, mandibular spaces, hypopharynx 
count and normal PTT and aPTT values, he was diagnosed with refractory ITP.

Facial-enhanced computed tomography revealed severe narrowing of the pharyngeal airway space. Marked soft tissue swelling was observed with isodensity in the left masticatory and submandibular spaces and hypopharynx. The patient complained of worsening respiration in the ER. The expanding hemorrhage was deemed to potentially result in a compromised airway with a life-threatening outcome. Therefore, the surgical wound from the dental implant was opened to evacuate the hematoma and an emergency tracheostomy was performed under local anesthesia and intravenous sedation to maintain airway patency. The patient was then admitted to the intensive care unit (ICU).

After tracheostomy, the intubation site also bled heavily. The patient was treated with antibiotics, high-dose steroids, and intravenous (IV) immunoglobulin $\mathrm{O}$ with a platelet infusion (platelet concentration 11 pints, $3600 \mathrm{~mL}$ ) continuously for 3 days. The aim was to elevate the platelet level to $80,000 / \mu \mathrm{L}$. To compensate for the blood loss ( $\mathrm{Hb}$ 8.7) associated with constant severe bleeding from a gingival surgical wound and tracheostomy site, a transfusion of filtered red blood cells and IV saline was performed.

Laboratory data after 3 days in the ICU showed a platelet count of $129,000 / \mu \mathrm{L}$ and other complete blood count $(\mathrm{CBC})$ values within normal ranges. Follow-up CT 3 days later revealed that the hemorrhage had not expanded further. Moreover, diminished soft tissue swelling was noted along the superficial and deep neck spaces compared with the swelling shown on the previous CT images (Fig. 2). Therefore, the patient was extubated without dyspnea. The patient showed resolution of the mouth floor swelling, and no additional bleeding was detected; thus, he was discharged 9 days after admission.

A follow-up visit 1 week after discharge revealed complete resolution of intra-oral and extra-oral swelling without superficial or deep neck infection. However, despite medication for ITP, the patient's platelet count decreased after 1 and 3 weeks (Table 1, Fig. 3). Four months later, final prosthetic implant restoration was performed in the prosthetic department.

\section{Discussion}

Most reports on oral bleeding associated with ITP describe preoperative management and management of spontaneous gingival oozing and bruising as oral symptoms of ITP $[8,10]$. Furthermore, only two reports have described bleeding after surgery or procedures in patients with ITP $[1,11]$ (Table 2), and these studies did not cover life-threatening massive bleeding after tooth extraction or dento-alveolar fracture, as in the present report. In addition, most published studies on severe

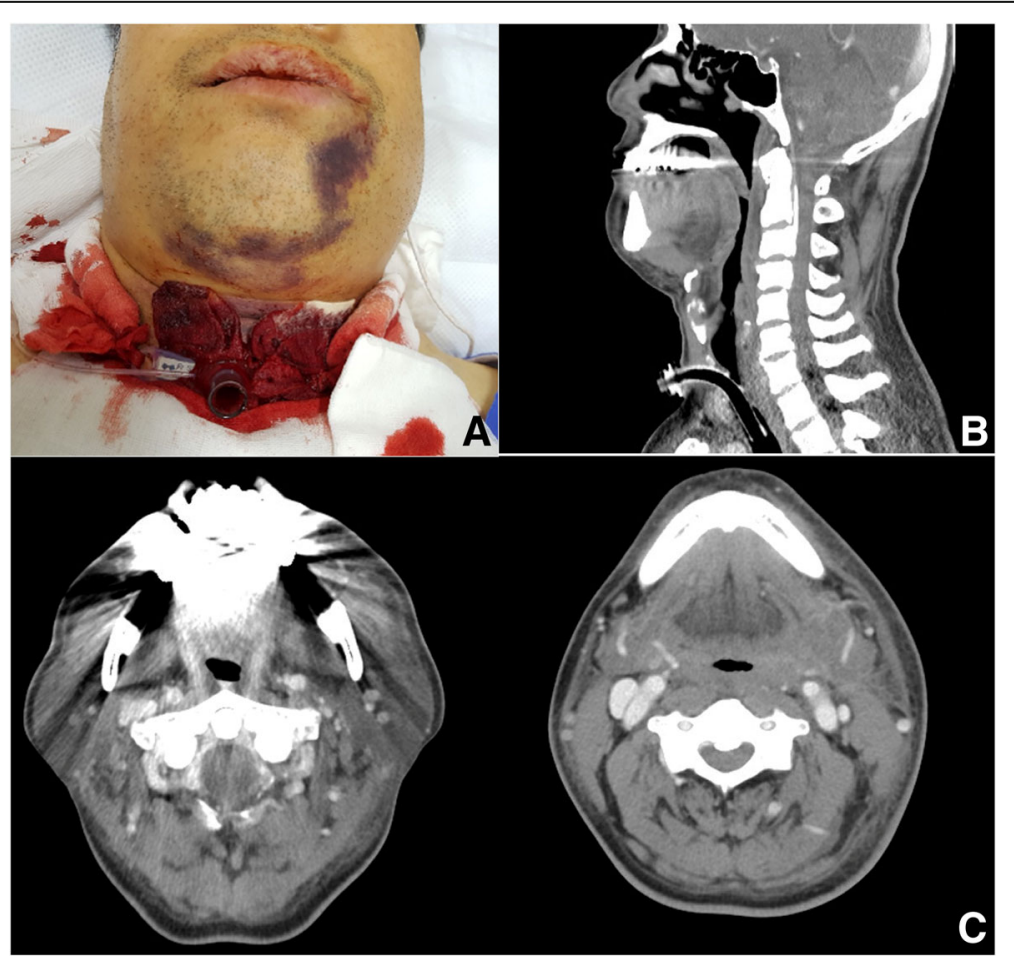

Fig. 2 a Constant bleeding at the tracheostomy site after an emergency tracheostomy. b Follow-up sagittal CT view and $\mathbf{c}$ axial CT views after 3 days showed decreased soft tissue swelling along the superficial and deep neck spaces at 3 days after tracheostomy 
Table 1 Laboratory value of the patient

\begin{tabular}{|c|c|c|c|c|c|c|c|c|c|c|c|c|c|c|c|c|c|}
\hline & \multicolumn{15}{|c|}{ Admission } & \multicolumn{2}{|c|}{ Follow-up } \\
\hline & $\begin{array}{l}1 \text { day } \\
16: 24\end{array}$ & $\begin{array}{l}1 \text { day } \\
\text { 21:08 }\end{array}$ & $\begin{array}{l}2 \text { day } \\
05: 39\end{array}$ & $\begin{array}{l}2 \text { day } \\
12: 28\end{array}$ & $\begin{array}{l}2 \text { day } \\
18: 02\end{array}$ & $\begin{array}{l}3 \text { day } \\
05: 06\end{array}$ & $\begin{array}{l}4 \text { day } \\
\text { 09:09 }\end{array}$ & $\begin{array}{l}4 \text { day } \\
12: 30\end{array}$ & $\begin{array}{l}4 \text { day } \\
20: 39\end{array}$ & $\begin{array}{l}5 \text { day } \\
08: 39\end{array}$ & $\begin{array}{l}6 \text { day } \\
08: 39\end{array}$ & $\begin{array}{l}6 \text { day } \\
18: 21\end{array}$ & $\begin{array}{l}7 \text { day } \\
08: 45\end{array}$ & $\begin{array}{l}8 \text { day } \\
08: 10\end{array}$ & $\begin{array}{l}9 \text { day } \\
10: 28\end{array}$ & 1 week & 3 week \\
\hline $\mathrm{F}-\mathrm{RBC}$ & & & 250 & 250 & 250 & & & & & & & & & & & & \\
\hline PLT & 2000 & 1600 & & & & & & & & & & & & & & & \\
\hline A-PLT & & & & 640 & & & & & & & 180 & & & & 289 & & \\
\hline FFP & & & 340 & & & & & & & & & & & & & & \\
\hline Steroid & 62.5 & & 62.5 & & & 62.5 & 62.5 & & & 62.5 & 62.5 & & 62.5 & 62.5 & 62.5 & 60 & 40 \\
\hline IVIG & 80 & & 80 & & & & & & & & & & & & & & \\
\hline
\end{tabular}

F-RBC filterd RBC ( $\mathrm{ml})$, PLT platelet concentrate $(\mathrm{ml}), A-P L T$ plateletpheresis $(\mathrm{ml})$, FFP fresh frozen plasma $(\mathrm{ml})$, steroid; corticosteroid (admission: solumedrol, $\mathrm{mg}$, IV, discharge: solondo, mg), IVIG intravenous immunoglobulin (IV-globulin SN, g, IV)

postoperative hemorrhage after dental implant surgery mention that the majority of life-threatening hemorrhages result from inadequate surgical skill and damage to an anatomical structure, such as rupture of the lingual artery or mandibular lingual cortex perforation, which typically occurs in the anterior region including the premolars between the mental foramens [12-14] (Fig. 4). The dental implant in this case report was placed in the posterior mandibular area, which had no atrophic status, and no anatomic structural damage or lingual cortex perforation had occurred.

The present report shows a life-threatening hemorrhage after dental implant surgery in a patient with ITP, which is an autoimmune disorder, characterized by both immunemediated platelet destruction and suppressed platelet production in the absence of other causes of thrombocytopenia. The role of platelets as a component of primary hemostasis is highly critical and starts the cascade of thrombus formation. Blood platelet levels are normally within the broad range of $150-400 \times 10^{3} / \mu \mathrm{L}$. Therefore, decreased production of platelets, increased platelet destruction and consumption, abnormal platelet distribution, and dilution or loss of platelets can induce congenital thrombocytopenia, an impaired bleeding tendency, and other primary hemostasis abnormalities. Therefore, ITP is a potentially life-threatening disease

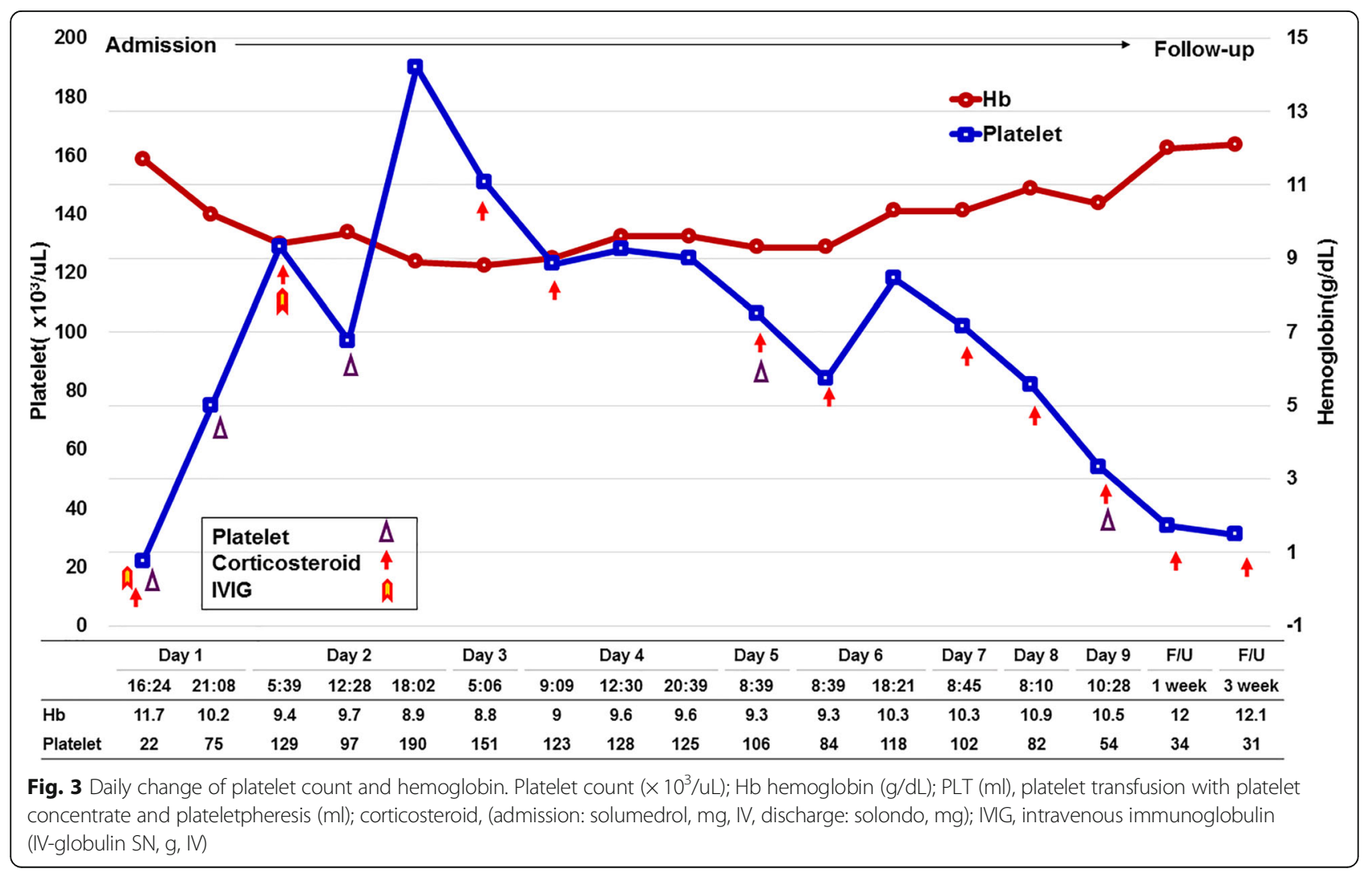


Table 2 Reported cases of oral hemorrhage after surgery or procedure in oral and maxillofacial area

\begin{tabular}{|c|c|c|c|c|c|c|c|}
\hline Reference & Age/sex & History of ITP & Other PMH & $\begin{array}{l}\text { Related surgery } \\
\text { or procedure }\end{array}$ & $\begin{array}{l}\text { Platelet count } \\
\text { before treatment }\end{array}$ & Management & $\begin{array}{l}\text { Platelet count } \\
\text { after treatment }\end{array}$ \\
\hline Finucane et al. (2003) [9] & $13 / M$ & $\begin{array}{l}\text { Known, } \\
\text { No med. }\end{array}$ & $N / S$ & $\begin{array}{l}\text { Tooth luxation } \\
\text { Partial alveolar bone fracture }\end{array}$ & 15,000 & IVIG & 70,000 \\
\hline Martini et al. (2011) [8] & $77 / F$ & $\begin{array}{l}\text { Newly, } \\
\text { No med }\end{array}$ & HTN, DM & Tooth extraction & 20,000 & PLT concentrate & 87,000 \\
\hline
\end{tabular}

ITP idiopathic thrombocytopenia, HTN hypertension, DM diabetes mellitus, IVIG intravenous immunoglobulin, PLT platelet transfusion

because of the tendency for massive bleeding and spontaneous hemorrhage as a serious complication; intracranial hemorrhage is the most frequent cause of death $[15,16]$.

ITP is diagnosed by exclusion. With no history of drugs or other comorbidities related to coagulopathy, a decrease in the platelet count on a CBC and a peripheral blood smear with a normal appearance should be observed. Consequently, bleeding time is prolonged. By contrast, PTT and aPTT are normal because the coagulant factor is normal. Moreover, bone marrow studies may reveal normal-to-increased levels of megakaryocytes varying from normal to immature [17].

Dental treatment is very closely related to bleeding. A bleeding tendency is critical in daily dental practice, particularly during oral surgery. Therefore, the evaluation of a patient's bleeding risk at the initial visit is crucial. Dentists must be aware that ITP is among the diseases related to an increased bleeding tendency because of a low platelet count. Although various hemostatic materials and specialized surgical techniques are used to prevent bleeding, their utility is limited in patients with ITP undergoing dental extraction because of their thrombocytopenic condition [9]. Therefore, both dentists and hematologists must be involved in treatment planning to avoid a life-threatening complication. They must discuss possible complications and perioperative management to ensure safe dental care [18]. In general, patients with platelet counts of at least $30 \times 10^{3} / \mu \mathrm{L}$ require no treatment unless a procedure inducing blood loss is required, such as a dental extraction [10], which can result in major bleeding complications in patients with platelet counts lower than $100 \times 10^{3} / \mu \mathrm{L}$ [19]. Some guidelines for the management of ITP in adults suggest the following recommendations for safe platelet counts: $10 \times 10^{3} /$ $\mu \mathrm{L}$ for routine dentistry, $30 \times 10^{3} / \mu \mathrm{L}$ for tooth extraction, $30 \times 10^{3} / \mu \mathrm{L}$ for a regional dental block, $50 \times 10^{3} / \mu \mathrm{L}$ for minor surgery, and $80 \times 10^{3} / \mu \mathrm{L}$ for major surgery [20]. Other guidelines for the treatment of ITP suggest similar recommendations, as follows: platelet counts of $20-30 \times 10^{3} / \mu \mathrm{L}$ for simple dental prophylaxis, $43 \times 10^{3} /$ $\mu \mathrm{L}$ for simple dental extractions, and $45 \times 10^{3} / \mu \mathrm{L}$ for more complex procedures [19].

A standard plan for adult patients with a platelet count of at least $30 \times 10^{3} / \mu \mathrm{L}$ is monitoring only, without intervention. However, when platelet counts decrease below $30 \times 10^{3} / \mu \mathrm{L}$, oral corticosteroids must be administered. If a rapid increase in platelet counts is required because of life-threatening bleeding, such as an intracranial hemorrhage or severe organ bleeding, as in the present study, the administration of IV immunoglobulin and/or high-dose corticosteroids is recommended [21]. In an emergency situation such as that observed in our case, platelet transfusions are also necessary [22]. The patient's platelet count was $129 \times 10^{3} / \mu \mathrm{L}$ after 3 days in the ICU with platelet transfusion and high-dose corticosteroid and

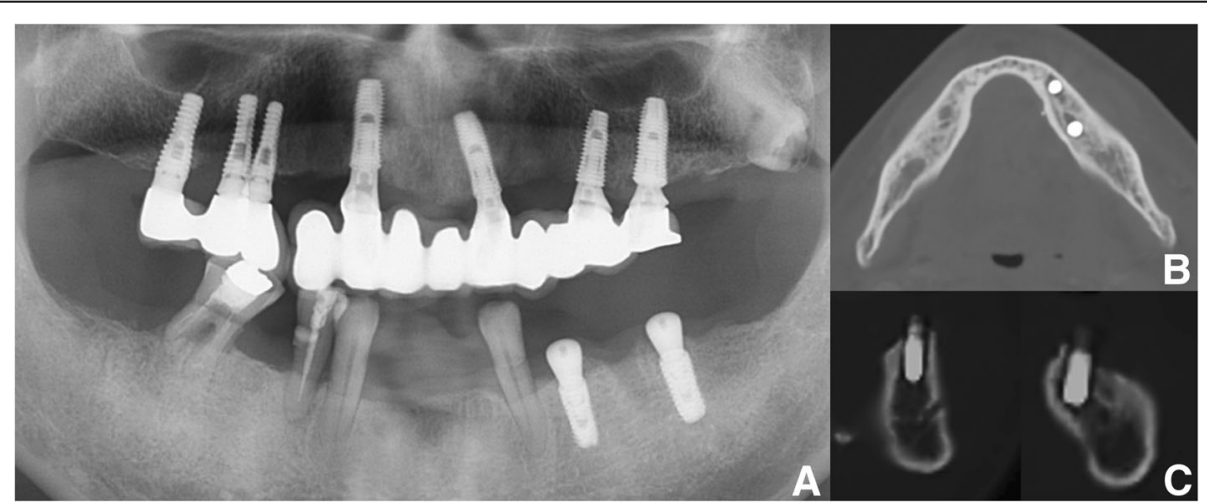

Fig. 4 a Panoramic view: dental implant installation state on mandible Lt. Posterior area (bleeding area). b Axial CT view and c sagittal CT view on implant site showed adequate placement of dental implant without lingual cortex perforation and damage of adjacent anatomic structure. The dental implant installation in the left posterior mandibular area 
IV immunoglobulin administration. However, despite treatment, his platelet count decreased to $30 \times 10^{3} / \mu \mathrm{L}$ after 1 month. Such patients unable to maintain a safe platelet count with first-line treatment are defined as having refractory ITP. Excessively low platelet count resulting from refractory ITP is a strong contraindication for any surgical procedure [23].

According to the past history of the patient in this case, tooth extraction was performed 1 month before dental implantation and no abnormal bleeding events occurred. Additionally, the patient took no medication for ITP for several years and only visited his hematologist annually. The dentist at the local dental clinic may have considered the ITP to be stable because the patient was not taking medication such as for hypertension or diabetes. Consequently, dental implant surgery was considered safe because no bleeding events had occurred during a previous tooth extraction and maxillary dental implant surgery performed several years previously. The absence of relevant medication history, such as anticoagulants, does not necessarily indicate that a patient can safely undergo an operation. The dentist was unfamiliar with ITP; nevertheless, a preoperative evaluation should have been performed, including a $\mathrm{CBC}$ and tests for platelet count, PTT, international normalized ratio (INR), and a PTT [24]. Many dentists underestimate the bleeding risk of procedures. Moreover, some dentists often feel inadequately trained to manage these patients in the event of any bleeding complication. However, paying attention to basic procedures such as history taking, physical examination, and related laboratory blood tests can prevent events such as excessive bleeding.

Most patients with ITP and other hematologic diseases can be managed safely during dental procedures if dentists take the nature and severity of these diseases into consideration. Exact medical history taking is necessary for all patients who will undergo surgical treatment. Vital signs should be measured and the need for additional preoperative tests and their type should be determined. Practitioners must also involve a hematologist for the evaluation of the medical condition and treatment planning of each patient.

Patients with chronic ITP frequently do not require comprehensive medication for daily life, and this lack of regular medication usage can sometimes lead practitioners or patients to underestimate the potential life-threatening risk of ITP. This report presented the emergency management of a life-threatening postoperative hemorrhage after dental implant surgery in an adult with chronic ITP. However, such events are preventable with adequate perioperative evaluation and management for ITP.

\section{Conclusion}

For a safe and satisfactory outcome for implantation in ITP patients, we recommend (1) obtaining a thorough past medical history with adequate preoperative laboratory tests such as $\mathrm{CBC}$, platelet count, bleeding time, PT, INR, and aPTT; (2) not relying on the dentist's own decision when evaluating a patient's medical status; (3) multidisciplinary involvement among dentists, hematologists, and other related physicians; and (4) perioperative platelet transfusion and corticosteroid and IV immunoglobulin administration to achieve suitable platelet count and function when a surgical procedure is needed.

Abbreviation

ITP: Idiopathic thrombocytopenic purpura

\section{Acknowledgements}

This research was supported by Kyungpook National University Bokhyeon Research Fund, 2015.

\section{Funding}

This study received no specific grant from any funding agency in the public, commercial, or not-for-profit sectors.

Availability of data and materials

Not applicable. (Data sharing is not applicable to this article as no datasets were generated or analyzed during the current study.)

\section{Authors' contributions}

STL drafted the manuscript. JWK and STL participated in the patient treatment. STL and TGK critically revised the manuscript. All authors read and approved the final manuscript.

Ethics approval and consent to participate Not applicable.

\section{Consent for publication}

Written informed consent was obtained from the patient for the publication of this report and any accompanying images.

\section{Competing interests}

The authors declare that they have no competing interests.

\section{Publisher's Note}

Springer Nature remains neutral with regard to jurisdictional claims in published maps and institutional affiliations.

Received: 9 October 2018 Accepted: 30 October 2018

Published online: 10 December 2018

References

1. Bonaccio M, Di Castelnuovo A, Costanzo S, De Curtis A, Donati MB, Cerletti C, de Gaetano G, lacoviello L (2016) Age-sex-specific ranges of platelet count and all-cause mortality: prospective findings from the MOLI-SANI study. Blood 127:1614-1616

2. George JN, Woolf SH, Raskob GE, Wasser JS, Aledort LM, Ballem PJ, Blanchette VS, Bussel JB, Cines DB, Kelton JG, Lichtin AE, McMillan R, Okerbloom JA, Regan DH, Warrier I (1996) Idiopathic thrombocytopenic purpura: a practice guideline developed by explicit methods for the American Society of Hematology. Blood 88:3-40

3. Cortelazzo S, Finazzi G, Buelli M, Molteni A, Viero P, Barbui T (1991) High risk of severe bleeding in aged patients with chronic idiopathic thrombocytopenic purpura. Blood 77:31-33

4. Cines DB, Blanchette VS (2002) Immune thrombocytopenic purpura. N Engl J Med 346:995-1008 
5. Reich W, Kriwalsky MS, Wolf HH, Schubert J (2009) Bleeding complications after oral surgery in outpatients with compromised haemostasis: incidence and management. Oral Maxillofac Surg 13:73-77

6. Givol N, Goldstein G, Peleg O, Shenkman B, Zimran A, Elstein D, Kenet G (2012) Thrombocytopenia and bleeding in dental procedures of patients with Gaucher disease. Haemophilia 18:117-121

7. Martini MZ, Lopez JS Jr, Gendler JL, da Fonseca EV, Soares HA, Franzi SA (2007) Idiopathic thrombocytopenic purpura presenting as post-extraction hemorrhage. J Contemp Dent Pract 8:43-49

8. Cohen YC, Djulbegovic B, Shamai-Lubovitz O, Mozes B (2000) The bleeding risk and natural history of idiopathic thrombocytopenic purpura in patients with persistent low platelet counts. Arch Intern Med 160:1630-1638

9. Fillmore WJ, Leavitt BD, Arce K (2013) Dental extraction in the thrombocytopenic patient is safe and complications are easily managed. $J$ Oral Maxillofac Surg 71:1647-1652

10. Tarantino MD, Fogarty PF, Shah P, Brainsky A (2015) Dental procedures in 24 patients with chronic immune thrombocytopenia in prospective clinical studies of eltrombopag. Platelets 26:93-96

11. Chen T, Chen Z, Zhang S, Zhang K, Wang L (2015) Development and validation of a LC-MS/MS method for quantification of hetrombopag for pharmacokinetics study. Springerplus 4:652

12. Tomljenovic B, Herrmann S, Filippi A, Kuhl S (2016) Life-threatening hemorrhage associated with dental implant surgery: a review of the literature. Clin Oral Implants Res 27:1079-1084

13. Dubois L, de Lange J, Baas E, Van Ingen J (2010) Excessive bleeding in the floor of the mouth after endosseus implant placement: a report of two cases. Int J Oral Maxillofac Surg 39:412-415

14. Woo BM, Al-Bustani S, Ueeck BA (2006) Floor of mouth haemorrhage and life-threatening airway obstruction during immediate implant placement in the anterior mandible. Int J Oral Maxillofac Surg 35:961-964

15. Nugent D, McMillan R, Nichol JL, Slichter SJ (2009) Pathogenesis of chronic immune thrombocytopenia: increased platelet destruction and/or decreased platelet production. Br J Haematol 146:585-596

16. Nurden P, Nurden AT (2008) Congenital disorders associated with platelet dysfunctions. Thromb Haemost 99:253-263

17. Stasi R, Provan D (2004) Management of immune thrombocytopenic purpura in adults. Mayo Clin Proc 79:504-522

18. Brown SA, Aledort LM, Lee CA, Barrowcliffe TW, Beeton K, Blanchette V, Bolland S, Goddard N, Goodeve A, Hoyer L, Kessler CM, Ljung R, Lollar P, Manco-Johnson M, Mariani G, Peerlinck K, Rivard G (2001) Optimal treatment regimens for patients with bleeding disorders. Haemophilia 7: 313-320

19. Provan D, Stasi R, Newland AC, Blanchette VS, Bolton-Maggs P, Bussel JB, Chong BH, Cines DB, Gernsheimer TB, Godeau B, Grainger J, Greer I, Hunt BJ, Imbach PA, Lyons G, McMillan R, Rodeghiero F, Sanz MA, Tarantino M, Watson S, Young J, Kuter DJ (2010) International consensus report on the investigation and management of primary immune thrombocytopenia. Blood 115:168-186

20. British Committee for Standards in Haematology General Haematology Task F (2013) Guidelines for the investigation and management of idiopathic thrombocytopenic purpura in adults, children and in pregnancy. $\mathrm{Br} J$ Haematol 120:574-596

21. Neunert C, Lim W, Crowther M, Cohen A, Solberg L Jr, Crowther MA (2011) American Society of $\mathrm{H}$. the American Society of Hematology 2011 evidencebased practice guideline for immune thrombocytopenia. Blood 117: 4190-4207

22. Provan D, Newland AC (2011) Guidelines for immune thrombocytopenia. N Engl I Med 364:580-581 author reply 581

23. Portielje JE, Westendorp RG, Kluin-Nelemans HC, Brand A (2001) Morbidity and mortality in adults with idiopathic thrombocytopenic purpura. Blood 97:2549-2554

24. Dougall A, Fiske J (2008) Access to special care dentistry, part 5. Safety. Br Dent J 205:177-190

\section{Submit your manuscript to a SpringerOpen ${ }^{\circ}$ journal and benefit from:}

- Convenient online submission

- Rigorous peer review

- Open access: articles freely available online

- High visibility within the field

- Retaining the copyright to your article

Submit your next manuscript at $\boldsymbol{\nabla}$ springeropen.com 